\title{
A multipolymer system for organocatalytic alcohol oxidation
}

\author{
Tracy Yuen Sze But, ${ }^{a}$ Yousuke Tashino, ${ }^{b}$ Hideo Togo ${ }^{b}$ and Patrick H. Toy* ${ }^{a}$ \\ ${ }^{a}$ Department of Chemistry, The University of Hong Kong, Pokfulam Road, Hong Kong, People's Republic of \\ China. Fax: 8522857 1586; Tel: 8522859 2167; E-mail: phtoy@hku.hk \\ ${ }^{b}$ Department of Chemistry, Faculty of Science, Chiba University, Yayoi-cho 1-33, Inage-ku, Chiba 263-8522, \\ Japan.
}

\section{This submission was created using the RSC Communication Template (DO NOT DELETE THIS TEXT) (LINE INCLUDED FOR SPACING ONLY - DO NOT DELETE THIS TEXT)}

\begin{abstract}
A system involving two polymer-supported reagents for the selective and organocatalytic oxidation of alcohols to aldehydes or ketones has been developed in which both polymeric reagents can be recovered and reused.
\end{abstract}

Polymer-supported reagents, ${ }^{1}$ including organic catalysts, ${ }^{2}$ have become widely used in organic synthesis and a great variety of these materials have been reported. Most of the supports used to immobilize reagents are insoluble, and as such, the attached functional groups react heterogeneously. Thus one of the major limitations in using such supported reagents is that they generally can not be used together in reactions that require the interaction of two or more reagents with one another prior to reaction with the substrate, such as would be the case in Mitsunobu reactions. They can only be used together in reactions that involve the sequential reaction of the supported reagents with the substrate, and a handful of such applications have been reported. ${ }^{3,4}$

Only when a soluble carrier ${ }^{5}$ is used for immobilization can a polymer-supported reagent or substrate be used to react with another polymer-supported substrate or reagent. ${ }^{6,7}$ To our knowledge, there are only two published exceptions to this: (1) the report by Murphy et al., in which an insoluble anion exchange resin was used to cleave tertiary amines from REM resin, ${ }^{8}$ and (2) the report by Ley et al. in which supported perchlorate and nitroxyl reagents oxidized alcohols to carboxylic acids. $^{9} \quad$ Along these lines, we have recently described the first example where two soluble polymer-supported reagents react with one another prior to reacting with the substrate in the context of organic synthesis. The report describes Mitsunobu reactions that involve polymer-supported phosphine and azodicarboxylate reagents. ${ }^{10}$ Herein, we present an extension of this concept to the development of a multipolymer system for the selective and organocatalytic oxidation of alcohols to aldehydes or ketones, in which one polymeric reagent is non-cross-linked and becomes soluble as the reaction progresses and the other is cross-linked and remains insoluble throughout the process.

We have previously described polymer-supported reagents for use in various oxidation reactions, including a fluroinated ketone for use in dioxirane mediated reactions, ${ }^{11}$ sulfoxides for use in Swern oxidation reactions, ${ }^{12}$ and recyclable polystyrenesupported diacetoxyiodosobenzene $(\mathbf{1}, \text { PSDIB })^{13,14}$ for use in a variety of rearrangement reactions. ${ }^{15,16}$ We subsequently found that $\mathbf{1}$, in conjunction with a nitroxyl radical catalyst, ${ }^{17}$ can oxidize alcohols to either aldehydes or ketones, ${ }^{18}$ or carboxylic acids. ${ }^{19}$ Thus we were eager to see if $\mathbf{1}$ could be used together with a polymer-supported nitroxyl reagent, as shown in Scheme 1 .

A variety of 2,2,6,6-tetramethyl-1-piperidinyloxy (TEMPO) regents have been recently reported that use both insoluble ${ }^{20}$ and soluble ${ }^{21}$ polymer supports in oxidation reactions. However, due to the increased swelling of the JandaJel $(J J)$ resins in organic solvents, ${ }^{22}$ and their overall ease of use, we decided to use this polymer platform as our support for TEMPO. Thus, 4-hydroxyTEMPO (1.2 eq) was attached to $J J-\mathrm{CH}_{2} \mathrm{Cl}$ (ca. $2.0 \mathrm{mmol} \mathrm{Cl} \mathrm{g}{ }^{-1}$ ) using $\mathrm{NaOH}(3 \mathrm{eq})$ and $\mathrm{Bu}_{4} \mathrm{NI}(0.1 \mathrm{eq})$ in $\mathrm{CH}_{2} \mathrm{Cl}_{2} / \mathrm{H}_{2} \mathrm{O}(40: 1)$ at rt for $24 \mathrm{~h}$. The polymer was filtered, washed sequentially with additional $\mathrm{CH}_{2} \mathrm{Cl}_{2}, \mathrm{Et}_{2} \mathrm{O}$ and hexanes, and dried to afford 2 in $84 \%$ yield. The nitrogen content of 2 was measured by elemental analysis to be $2.88 \%$, which corresponds to a nitroxyl loading level of $2.0 \mathrm{mmol} \mathrm{TEMPO}^{-1}$.

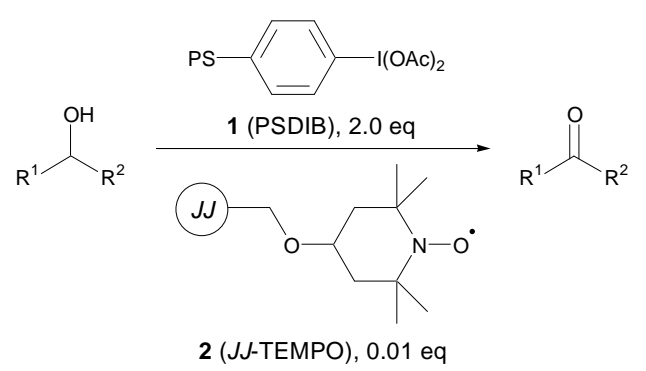

Scheme 1 Simultaneous use of PSDIB (1) and JJ-TEMPO (2) for alcohol oxidation.

Gratifyingly, initial attempts to use $\mathbf{1}$ and $\mathbf{2}$ simultaneously for the selective oxidation of 2-phenylethanol to the corresponding aldehyde were successful and the optimal reaction conditions were found to be 2.0 eq of $\mathbf{1}$ in conjunction with 0.01 eq of 2 in 1,2-dichloroethane at $70{ }^{\circ} \mathrm{C}$. Having established the feasibility of our strategy, we studied the oxidation of a wide range of primary and secondary aliphatic, allylic and benzylic alcohols (Table 1). Yields of all aldehyde and ketone products were high, with the activated benzylic alcohols being formed more rapidly. Even sterically hindered secondary alcohols could be oxidized using our multipolymer system in good to excellent yield after extended reaction times (Table 1, entries 4 and 5). Furthermore, no evidence of acid formation was observed with any of the primary alcohols used. Notably, the products could be isolated efficiently after several filtration and concentration operations (see experimental section).

We next examined if it was possible to reuse the mixture of the excess, unreacted 1 together with 2 recovered at the end of each oxidation reaction. Thus, the oxidation of 2-phenylethanol was performed 3 successive times using the recovered polymer mixture supplemented by additional $\mathbf{1}$ (so that 2 eq of the oxidant were used in each reaction). Even after the second recycling (third oxidation reaction), the product was formed in nearly quantitative (98\%) yield (Table 1 , entry 1 ).

In conclusion, we have developed a multipolymer system for the selective, and organocatalytic oxidation of alcohols to aldehydes or ketones in which the polymeric reagents can be recovered and reused. This process is noteworthy because the polymeric reagents react with one another ( $\mathbf{1}$ oxidizes $\mathbf{2}$ ) prior to reaction with the substrate. Furthermore, it is environmentally friendly since the polymers can be recycled and it should be ammenable to use in medicinal chemistry parallel synthesis procedures where small quantities of highly pure products are 
desired with minimal purification necessary. On going studies include further examining the scope of this reaction system, its scale-up and the recyclability of spent 1.

Table 1 Results of alcohol oxidation using 1 (2 eq) and 2 (0.01 eq) ${ }^{a}$

\begin{tabular}{|c|c|c|c|}
\hline Entry & Starting material & Time $(\mathrm{h})^{b}$ & Yield (\%) \\
\hline 1 & 2-phenylethanol & 5 & $\begin{array}{l}\text { cycle 1: } 96^{c} \\
\text { cycle 2: } 95^{c} \\
\text { cycle 3: } 98^{c}\end{array}$ \\
\hline 2 & cyclohexylmethanol & 24 & $77^{d}$ \\
\hline 3 & cyclohexanol & 7 & $71^{c}$ \\
\hline 4 & (-)-menthol & 48 & $90^{d}$ \\
\hline 5 & $\begin{array}{c}\text { 1,2:4,5-di-O-cyclohexylidene- } \\
\text { B-D-fructopyranose }\end{array}$ & $60^{e}$ & $67^{d}$ \\
\hline 6 & 2-cyclohexen-1-ol & 5 & $100^{c}$ \\
\hline 7 & cinnamyl alcohol & 6 & $71^{d}$ \\
\hline 8 & benzyl alcohol & 5 & $80^{d}$ \\
\hline 9 & benzhydrol & $7^{e}$ & $100^{d}$ \\
\hline 10 & benzoin & 12 & $100^{d}$ \\
\hline 11 & 1-(4-bromophenyl)ethanol & 12 & $100^{d}$ \\
\hline 12 & 1,2,3,4-tetrahydro-1-naphthol & 7 & $91^{d}$ \\
\hline
\end{tabular}

${ }^{a}$ All aldehyde and ketone products are known in the literature or commercially available. ${ }^{b}$ Time required for complete consumption of starting alcohol. ${ }^{c}$ GC yield. ${ }^{d}$ Isolated yield. ${ }^{e} 0.05$ eq 2 was used.

\section{Experimental}

\section{General procedure for alcohol oxidation}

$J J$-TEMPO (2, $0.001 \mathrm{mmol})$ and PSDIB (1, $0.2 \mathrm{mmol})$ were added to a solution of alcohol $(0.1 \mathrm{mmol})$ in $\mathrm{ClCH}_{2} \mathrm{CH}_{2} \mathrm{Cl}(2$ $\mathrm{mL}$ ). The mixture was shaken at $70{ }^{\circ} \mathrm{C}$ until the alcohol was no longer detectable by TLC analysis. At this time the reaction was filtered to remove a mixture of excess $\mathbf{1}$ and catalyst 2, and concentrated in vacuo. The resulting residue was then filtered through a plug of silica gel (20\% EtOAc in hexanes) to remove reacted 1. Removal of the solvent afforded the desired product that was essentially pure as determined by ${ }^{1} \mathrm{H}$ and ${ }^{13} \mathrm{C}$ NMR analysis. Additionally, LRMS analysis indicated the correct molecular mass of all products, which were found to be spectroscopically identical to authentic samples of them.

\section{Acknowledgements}

Financial support was provided by the Research Grants Council of the Hong Kong Special Administrative Region, P. R. of China (Project No. HKU 7112/02P).

\section{Notes and references}

1 (a) S. V. Ley, I. R. Baxendale, R. N. Bream, P. S. Jackson, A. G. Leach, D. A. Longbottom, M. Nesi, J. S. Scott, R. I. Storer and S. J. Taylor, J. Chem. Soc., Perkin Trans. 1, 2000, 3815; (b) S. Bräse, F. Lauterwasser and R. E. Ziegert, Adv. Synth. Catal., 2003, 345, 869.

2 M. Benaglia, A. Puglisi and F. Cozzi, Chem. Rev., 2003, 103, 3401.

3 (a) G. Cainelli, M. Contento, F. Manescalchi and R. Regnoli, J. Chem. Soc., Perkin Trans. 1, 1980, 2516; (b) B. J. Cohen, M. A. Kraus and A. Patchornik, J. Am. Chem. Soc., 1981, 103, 7620; (c) D. E. Bergbreiter and R. Chandran, J. Am. Chem. Soc., 1985, 107, 4792; (d) M. Bessodes and K. Antonakis, Tetrahedron Lett., 1985, 26, 1305; (e) S. L. Regen and M. Kodomari, J. Chem. Soc., Chem. Commun., 1987, 1428; (f) J. J. Parlow, Tetrahedron Lett., 1995, 36, 1395.

4 For examples of substrates being detached from one polymer in order to react with a different polymeric reagent, see: (a) A. Warshawsky, R. Kalir and A. Patchornik, J. Am. Chem. Soc., 1978, 100, 4544; (b) J. Rebek, Jr., Tetrahedron, 1979, 35, 723; (c) Y. Hamuro, M. A. Scialdone and W. F. DeGrado, J. Am. Chem. Soc., 1999, 121, 1636; (d) M. Gravel, K. A. Thompson, M. Zak, C. Berube and D. G. Hall, J. Org. Chem., 2002, 67, 3; (e) J. C. Pelletier, A. Khan and Z. Tang, Org. Lett., 2002, 4, 4611.

5 (a) P. H. Toy and K. D. Janda, Acc. Chem. Res., 2000, 33, 546; (b) T. J. Dickerson, N. N. Reed and K. D. Janda, Chem. Rev., 2002, 102, 3325; (c) D. E. Bergbreiter, Chem. Rev., 2002, 102, 3345.

6 For examples of soluble polymer-supported reagents or substrates reacting with insoluble polymer-supported reagents or substrates, see: (a) H. Frank and H. Hagenmaier, Experientia, 1975, 31, 131; (b) G. Heusel, G. Bovermann, W. Göhring and G. Kung, Angew. Chem. Int. Ed., 1977, 16, 642; (c) D. E. Bergbreiter and R. Chandran, J. Am. Chem. Soc., 1987, 109, 174; (d) H. Han and K. D. Janda, Angew. Chem. Int. Ed., 1997, 36, 1731; (e) P. H. Toy, T. S. Reger and K. D. Janda, Org. Lett., 2000, 2, 2205.

7 For an report of two different soluble-polymer bound substrates reacting with one another in a convergent and combinatorial manner, see: J.-M. Ahn, P. Wentworth, Jr. and K. D. Janda, Chem. Commun., 2003, 480.

8 X. H. Ouyang, R. W. Armstrong and M. M. Murphy, J. Org. Chem. 1998, 63, 1027.

9 K. Yasuda and S. V. Ley, J. Chem. Soc., Perkin Trans. 1, 2002, 1024.

10 A. M. Harned, H. S. He, P. H. Toy, D. L. Flynn and P. R. Hanson, J. Am. Chem. Soc., 2005, 127, 52.

11 J. T. W. Kan and P. H. Toy, Tetrahedron Lett., 2004, 45, 6357.

12 (a) M. K. W. Choi and P. H. Toy, Tetrahedron, 2003, 59, 7171; (b) M. K. W. Choi and P. H. Toy, Tetrahedron, 2004, 60, 2875.

13 For a review of polymer-supported hypervalent iodine reagents, see: H. Togo and K. Sakuratani, Synlett, 2002, 1966. For a review of hypervalent iodine reagents in oxidation reactions, see: $\mathrm{H}$. Tohma and Y. Kita, Adv. Synth. Catal., 2004, 346, 111.

14 (a) S. V. Ley, A. W. Thomas and H. Finch, J. Chem. Soc., Perkin Trans. 1, 1999, 669; (b) H. Tohma, S. Takizawa, T. Maegawa and Y. Kita, Angew. Chem. Int. Ed., 2000, 39, 1306; (c) S. Ficht, M. Mülbaier and A. Giannis, Tetrahedron, 2001, 57, 4863.

15 (a) H. Togo, G. Nogami and M. Yokoyama, Synlett, 1998, 534; (b) H. Togo, S. Abe, G. Nogami and M. Yokoyama, Bull Chem. Soc. Jpn., 1999, 72, 2351; (c) K. Sakuratani and H. Togo, ARKIVOC, 2003, 11.

16 J.-M. Chen and X. Huang, Synthesis, 2004, 2459

17 For a review of nitroxyl radical mediated oxidation reactions, see: $\mathrm{R}$. A. Sheldon and I. W. C. E. Arends, Adv. Synth. Catal., 2004, 346, 1051.

18 K. Sakuratani and H. Togo, Synthesis, 2003, 21.

19 Y. Tashino and H. Togo, Synlett, 2004, 2010.

20 A. Dijksman, I. W. C. E. Arends and R. A. Sheldon, Synlett, 2001, 102.

21 (a) C. Tanyeli and A. Gumus, Tetrahedron Lett., 2003, 44, 1639; (b) G. Pozzi, M. Cavazzini, S. Quici, M. Benaglia and G. Dell'Anna, Org. Lett., 2004, 6, 441; (c) P. Ferreira, W. Hayes, E. Phillips, D. Rippon and S. C. Tsang, Green Chem., 2004, 6, 310; $(d)$ P. Ferreira, E. Phillips, D. Rippon, S. C. Tsang and W. Hayes, J. Org. Chem., 2004, 69, 6851.

22 (a) P. H. Toy and K. D. Janda, Tetrahedron Lett., 1999, 40, 6329; (b) P. H. Toy, T. S. Reger, P. Garibay, J. C. Garno, J. A. Malikayil, G.Y. Liu and K. D. Janda, J. Comb. Chem., 2001, 3, 117; (c) L.-J. Zhao, H. S. He, M. Shi and P. H. Toy, J. Comb. Chem., 2004, 6, 680. 
Table of contents graphic.

A system involving two polymer-supported reagents for the selective and organocatalytic oxidation of alcohols to aldehydes or ketones has been developed.

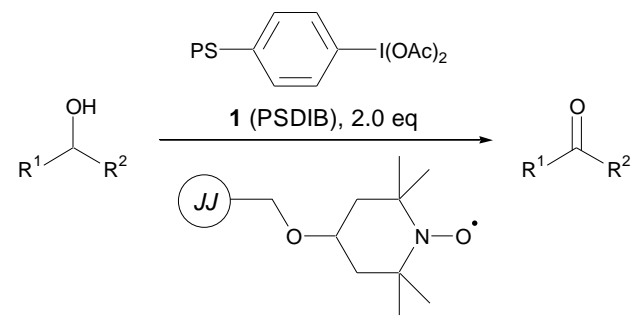

2 (JJ-TEMPO), 0.01 eq 
